

\title{
Kars Yöresine Ait Sözsüz Eserlerin Müzikal Analizi ve Çalgı Eğitiminde Kullanılabilirliği ${ }^{1}$
}

\author{
Şermin Uluman ${ }^{2}$ iD Murat Kâmil İnanıcı ${ }^{3}$ iD
}

Atıf: Uluman, Ş. ve İnanıcı, M. K. (2020). Kars yöresine ait sözsüz eserlerin müzikal analizi ve çalgı eğitiminde kullanılabilirliği. e- Kafkas Eğitim Araştırmaları Dergisi, 7, 458-472. doi:10.30900/kafkasegt.757964

\section{Araștırma Makalesi}

Geliş Tarihi:25.06.2020
Kabul Tarihi:01.12.2020

\section{$\ddot{\mathbf{O} z}$}

$\mathrm{Bu}$ çalışmada Kars yöresi Türk halk müziği sözsüz eserlerinin müzikal açıdan incelenmesi ve incelenen bu eserlerin çalgı eğitiminde kullanılabilirlik durumlarının belirlenmesi amaçlanmıştır. Çalışmanın ilk boyutunda Kars yöresi Türk halk müziği sözsüz eserlerinin müzikal analizinin yapılması amaciyla doküman incelemesi yöntemi kullanılmıştır. Doküman incelemesi sonucunda Kars yöresi Türk halk müziği sözsüz eserlerinin belirlenmesine yönelik TRT repertuarında ve Kültür Bakanlığı kaynaklarında bulunan Kars yöresine ait sözsüz eserler araştırmacı tarafından tespit edilmiştir. Tespit edilen sözsüz eserlerin; makam dizileri, ölçü birimleri, seyir özellikleri, ses genişliği, tiz ve pes sesleri müzikal açısından incelenerek analiz edilmiştir. Araştırmanın ikinci boyutunda ise incelenen eserlerin çalgı eğitiminde kullanılabilirliğini belirlemek amacıyla alan uzmanlarına yönelik araştırmacılar tarafından oluşturulan görüşme formu uygulanmıştır. Araştırmadan elde edilen bulgulara göre, Kars yöresine ait 48 adet sözsüz eser olduğu, Türk müziği makam analizleri sonucunda eserlerin; Buselik, Çargâh, Gülizar, Hicaz, Hüseyni, Hüzzam, Kürdi, Nikriz, Nişabur, Pençgâh, Rast, Segâh ve Uşşak makam dizisinde olduğu, usul analizleri sonucunda ise eserlerin; 2/4'lük, 3/4'lük, 4/4'lük, 6/4'lük, 7/4'lük, 3/8'lik, 5/8' lik, 6/8'lik, 7/8'lik, 8/8'lik, 9/8'lik, 10/8'lik, 12/8'lik, 18/8'lik, 20/8'lik ve 21/8'lik ölçü birimlerinde eserler olduğu tespit edilmiştir. Kars yöresine ait 48 adet sözsüz eserin çalgı eğitiminde, güzel sanatlar lisesi ve lisans eğitimi düzeyinde basit, orta ve ileri düzeylerde kullanım için uygun olduğu belirlenmiştir.

Anahtar Sözcükler: Türk halk müziği, Kars yöresi, müzikal analiz, müzik eğitimi, çalgı eğitimi

\section{Abstract}

This study aims to examine the non-verbal works of Turkish folk music of the Kars region from a musical point of view and to determine the usability of these pieces in instrument education. In the first dimension of the study, the document analysis method is used to make the musical analysis of non-verbal works of Turkish folk music of the Kars region. As a result of the document review, non-verbal works in the Kars region, which are in the TRT repertoire and the sources of the Ministry of Culture, have been determined by the researcher. Of the detected nonverbal works; Maqam scales, measurement units, navigational characteristics, pitch, and low-pitched sounds have been examined musically by the researchers. In the second dimension of the study, to determine the usability of the examined pieces in instrument education, an interview form is created and applied by the researchers for field experts. According to the findings, 48 non-verbal works belong to the Kars region. As a result of Turkish music maqam analysis, the works are place in Buselik, Çargâh, Gülizar, Hicaz, Hüseyni, Hüzzam, Kürdi, Nikriz, Nishapur, Pençgâh, Rast, Segâh and Uşşak maqam scale, as a result of the procedural analysis, it has been determined that the works are in $2 / 4,3 / 4,4 / 4,6 / 4,7 / 4,3 / 8,5 / 8,6 / 8,7 / 8,8 / 8,9 / 8,10 / 8,12 / 8,18 / 8,20 / 8$ and 21/8 units of measure. It has been determined that 48 non-verbal works belonging to the Kars region are suitable for use in simple, intermediate, and advanced levels at the level of fine arts high school and undergraduate education.

Keywords: Turkish folk music, Kars region, musical analysis, music education, instrument education.

\footnotetext{
${ }^{1} \mathrm{Bu}$ araştırma birinci yazarın hazırladığı yüksek lisans tezinden üretilmiştir.

${ }^{2}$ Millî Eğitim Bakanlığı, Türkiye.

${ }^{3}$ Sorumlu yazar, muratkamilinanici@ hotmail.com, Doktor Öğretim Üyesi, Atatürk Üniversitesi
} 


\section{Giriş}

Genel anlamda eğitim "bireyde davranış değiştirme, bireyin davranışında kendi yaşantısı yoluyla ve kasitlı olarak istendik değişme meydana getirme sürecidir" (Demirel, 2012, s. 44). Eğitim sürecinde birey hiç sahip olmadığı yeni bir davranışı kazanabilir, mevcut davranışları içinde eksik ve yetersiz olanları tamamlayabilir ve yanlış gelişmiş bir davranışını değiştirerek doğru davranışı kazanabilir (Görgen, 2017). Eğitim bireylerde bedensel, devinişsel, duyuşsal ve bilişsel davranışları bütünlük içerisinde geliştirmeyi amaçlar. Bu davranışların bireylerde bütünlük içerisinde kazandırmanın hedeflendiği alanlardan biri de sanat eğitimi alanları içerisinde önemli bir yere sahip olan müzik eğitimi alanıdır. Yalın ve özlü anlamıyla müzik eğitimi "bireye kendi yaşantısı yoluyla amaçlı olarak belirli müzikal davranışlar kazandırma ve onun müzikal davranışlarını değiştirme ve geliştirme sürecidir" (Uçan, 1997, s. 8).

Müzik eğitimi sürecinde halk müziklerinin kullanılmasının gerektiği düşüncesi, eğitimin yakından uzağa-çevreden evrene ilkesi bağlamında sürekli olarak tartışılmış, yerel ve ulusal müziklerin müzik eğitiminde kullanılmasının gerekliliği çeşitli müzik eğitimcileri tarafından savunulmuştur. Macar besteci, müzikolog ve müzik eğitimcisi Zoltan Kodaly bu fikri savunan müzik eğitimcilerinin başında gelmektedir. En mükemmel kişisel eserin, bir başyapıtın bile geleneksel müzik eserlerinin yerini tutamayacağını düşünen Kodaly, çocukların fiziksel, gelişimsel ve psikolojik ihtiyaçları için uygun olan müzikal materyallerin kendi toplumlarının halk şarkılarında bulunduğunu belirtmektedir (Peşinci, 2014; Küçük, 2019). Halk müziği eserleri, müzik eğitimi için ideal materyalleri sağlar. Bu sebeple müzik eğitiminde o ülkenin kendi ana dilindeki halk şarkıları kullanılmalıdır (Gürgen, 2007; Tufan, 2011; Avşar, 2018). Kodaly, halk müziğinin sesli aktarım geleneğiyle gelişmiş olduğundan çocukların kulak eğitimi ve müzik hafızasını geliştirmek için ideal olduğunu, ayrıca, müzik eğitimi sürecinde çocukların kendi yerel ve ulusal müziklerinde yer alan eserlerden başlayarak diğer ulusların eserlerine doğru müzikal bilgilerini genişlettikçe kendi kültürel müzikal miraslarının koruyucusu olacaklarını da düşünmektedir (Peşinci, 2014). Yerel ve ulusal kültürel özelliklerin yansıması olan ve müzik eğitiminin başlangıç aşamasında kullanımının önemli yararlar sağladığı düşünülen halk müzikleri, toplumların yaşam koşullarının yansıması olarak ortaya çıkan ve bu yansımaların duygusal, sanatsal ve estetik anlatımlarını içeren kültür ürünleridir (İnanıc1, 2017, s.1). Halk müzikleri genellikle isimleri bilinmeyen ve halkın içerisinde yaşayan sanatçılar tarafından üretilmiş (Demirsipahi, 1975, s.7), insanların yaşadıkları çeşitli olaylar karşısında oluşan duygularını, kendine özgü halk çalgılar ve edebi sözlerle ezgisel olarak ifade ettiği eserlerdir (Emnalar, 1998, s.27). Meydana geldiği mekân ve koşullar açısından kırsal kökenli olan halk müziğini, halkın yaşantısı içerisinde karşılaştığı doğal ve sosyal olayları toplumun ortak anlayışı ve beğeni biçimine bağlı olarak halkın kendi içinden yetişen sanatçıları tarafından oluşturulan müzik türü olarak tanımlamak mümkündür (İnanıc1, 2017). Halk müziklerinin kültürel miras olma özelliği, toplumsal belleğin korunmasına katkıda bulunmasının yanı sıra çocukların müzikal gelişimini sağlaması ve müzikal benliklerini geliştirmesi açısından da önemli bir eğitim aracı olarak görülmesini sağlamaktadır.

$\mathrm{Bu}$ bağlamda, müzik eğitiminde yerelden ulusala, ulusaldan evrensele gidilen yolda yöre müziklerinin eğitim materyali olarak kullanılması, unutulma ve kaybolma tehlikesi ile karşı karşıya olan kültür değerlerinin genel, mesleki ve özengen müzik eğitimi aracılığıyla gelecek kuşaklara aktarılması önemli bir husustur. Bu sebeple halk müziği eserlerinin ezgisel ve ritmik özelliklerinin incelenmesi, müzik eğitimi yoluyla hem eğitim alanında kullanılması hem de kültürel devamlılığın sağlanması açısından önem teşkil etmektedir.

Alan yazında çeşitli yörelere ait halk eserlerinin araştırılıp incelenmesi ve müzik eğitim anlayışının değişik aşamalarından yararlanması üzerine birçok akademik çalışma bulunmaktadır. Yapılan incelemeler sonucunda Kars yöresine ait Türk halk müziği sözsüz eserlerinin müzikal analizinin henüz yapılmamış ve müzik eğitiminde yararlanma yönünün değerlendirilmemiş olmasının bu çalışmanın özgün değeri açısından önemli olabileceği düşünülmektedir.

Bu çalışmada Kars yöresi Türk halk müziği sözsüz eserlerinin müzikal açıdan incelenmesi ve incelenen bu eserlerin mesleki müzik eğitimi veren kurumlarda çalgı eğitiminde kullanılabilirlik durumlarının belirlenmesi amaçlanmaktadır. Bu temel amaç doğrultusunda "TRT ve Kültür Bakanlığı kaynaklı Kars yöresine ait Türk halk müziği sözsüz eserlerinin müzikal analizi ve uzman akademisyenlerin bu eserlerin çalgı eğitiminde kullanılabilirlik durumları hakkındaki görüşleri 
nelerdir?" sorusu bu araştırmanın problem durumunu oluşturmaktadır. Bu probleme bağlı olarak araştırmada aşağıdaki sorulara cevap aranmıştır:

TRT ve Kültür bakanlığı kaynaklı Kars yöresine ait;

- $\quad$ Sözsüz eserlerin doküman analizi sonucu elde edilen müzikal analiz bulguları nelerdir?

- Sözsüz eserlerin mesleki müzik eğitimi veren kurumlarda çalg1 eğitiminde kullanılabilirlik durumlarına yönelik alan uzmanı akademisyenlerin görüşleri nelerdir?

\section{Yöntem}

\section{Araştırma Modeli}

Araştırma nitel araştırma modelinde tasarlanmıştır. Nitel araştırmalar gözlem, görüşme ve doküman inceleme gibi nitel veri toplama yöntemlerinin kullanıldığı, algıların ve olayların doğal ortamında gerçekçi ve bütüncül bir biçimde ortaya konmasına yönelik sürecin izlendiği araştırmalardır (Yıldırım ve Şimşek, 2011). Bu doğrultuda araştırma iki boyutlu olarak tasarlanmıştır. Araştırmanın ilk boyutunda Kars yöresi Türk halk müziği sözsüz eserlerinin müzikal analizinin yapılması amacıyla doküman incelemesi yöntemi kullanılmıştır. Doküman incelemesi yönteminin temel kaynağını oluşturan dokümanlar kamu kayıtları, kişisel belgeler, popüler kültür dokümanları ve filmleri, videoları ve resimleri içeren görsel dokümanlar şeklinde sınıflandırılabilmektedir (Merriam, 1998). Araştırmada Kars yöresi Türk halk müziği sözsüz eserlerinin belirlenmesine yönelik TRT repertuarında ve Kültür Bakanlığı kaynaklarında bulunan Kars yöresine ait sözsüz eserler araştırmacılar tarafindan tespit edilmiştir. Tespit edilen sözsüz eserlerin makam dizileri, ölçü birimleri, seyir özellikleri, ses genişliği, tiz ve pes sesleri araştırmacılar tarafından incelenmiş ve müzikal açıdan analiz edilmiştir. Araştırmacılar tarafindan analiz edilen Kars yöresi Türk halk müziği sözsüz eserlerinin makam dizileri, ölçü birimleri, seyir özellikleri, ses genişliği, tiz ve pes seslerin tespitlerinin doğruluk düzeylerine yönelik alan uzmanı akademisyenlerin görüşleri alınarak olası yanlışlar düzeltilmiştir. Araştırmanın ikinci boyutunda ise müzikal açıdan incelenen eserlerin mesleki müzik eğitimi veren güzel sanatlar liseleri ve lisans eğitimi çalg1 eğitiminde kullanılabilirliğine yönelik alan uzmanlarıyla görüşmeler gerçekleştirilmiştir. Görüşme önceden hazırlanmış soruların sorulduğu ve karşıdaki kişinin sorulara yanıtlar verdiği amaçlı bir söyleşidir (Kuş, 2003).

\section{Çalışma Grubu}

İki boyutlu olarak yürütülen araştırmanın birinci çalışma grubunu müzikal analizi yapılmak üzere TRT repertuarında ve Kültür Bakanlığı kaynaklarında bulunan Kars yöresine ait 48 adet Türk halk müziği sözsüz eserin bulunduğu dokümanlar oluşturmaktadır. Araştırmanın ikinci çalışma grubunu ise analizi yapılan eserlerin çalgı eğitiminde kullanılabilirliğini belirlemeye yönelik görüşlerine başvurulan alan uzmanı akademisyenler oluşturmaktadır. Akademisyenlerin belirlenmesinde yöre müziklerini bilmesi ve çalgı eğitiminde uzman olması gibi ölçütler temel alınmıştır. Bu bağlamda Kafkas Üniversitesi Devlet Konservatuarı'nda görev yapan ve bu ölçütleri karşılayan 3 akademisyen araştırmanın uzman grubunu oluşturmuştur. Uzman grubunun özellikleri incelendiğinde akademisyenlerin mesleki hizmet sürelerinin bir akademisyenin 14 yıl, iki akademisyenin 6 y1l olduğu görülmüştür. Ayrıca ana çalgılarının bağlama, keman ve piyano olduğu; akademik unvanlarının ise doçent doktor, doktor öğretim üyesi ve araştırma görevlisi olduğu belirlenmiştir.

\section{Veri Toplama Araçları}

Araştırmada veri toplama aracı olarak kullanılmak üzere kişisel bilgi formu, doküman listesi ve görüşme formu kullanılmıştır.

Kişisel bilgi formu araştırma kapsamında görüşme yapılacak olan akademisyenlerin mesleki süreleri, ana çalgılarının ne olduğu, bağlı bulundukları kurum vb. soruların yer aldığı ve araştırmacılar tarafindan hazirlanan formdur.

Araştırmada kullanılan doküman listesi TRT repertuarında ve Kültür Bakanlığı kaynaklarında bulunan Kars yöresine ait 48 adet Türk halk müziği sözsüz eserin bulunduğu formdur. Form hazırlanırken öncelikli olarak bu eserler listelenmiş ve makam dizileri, ölçü birimleri, seyir özellikleri, 
ses genişliği, tiz ve pes seslerin tespitini yapmak için araştırmacılar tarafindan müzikal açıdan incelenmiştir. Araştırmacılar tarafından yapılan analizlerin ve tespitlerin doğruluk düzeylerine yönelik alan uzmanlarının görüşleri alınarak olası yanlışlar düzeltilmiştir.

Araştırmada kullanılan görüşme formu müzikal açıdan analiz edilen Kars yöresi Türk halk müziği sözsüz eserlerinin çalgı eğitiminde kullanılabilirliğini belirlemek için alan uzmanlarına yönelik ilgili alanyazın ve uzman görüşleri doğrultusunda hazırlanmıştır. Görüşme formunda Kars yöresi Türk halk müziği sözsüz eserlerinin güzel sanatlar liseleri ve lisans düzeyi çalgı eğitiminde kullanılabilirlik durumlarını belirlemeye yönelik sorular bulunmaktadır.

\section{Veri Analizi}

Araştırmada ortaya çıkan verilerin çözümlenmesinde betimsel ve içerik analiz kullanılmıştır. Araştırmada öncelikle TRT repertuarında ve Kültür Bakanlığı kaynaklarında bulunan Kars yöresine ait eserlerin analiz edilmesini amaçlayan doküman incelemesi yoluyla elde edilen ve müzikal analizleri yapılan eserler betimsel analiz çözümlemesine tabi tutulmuştur. Betimsel analiz elde edilen verilerin daha önceden belirlenen temalara göre özetlendiği bir analiz türüdür (Yıldırım ve Şimşek, 2011). Veri analiz sonuçları frekans ve yüzde değerleriyle ifade edilmiştir. Araştırmanın ikinci aşamasında ise belirlenen eserler alan uzmanı akademisyenlerin görüşlerine sunularak çalg1 eğitiminde kullanılabilirlik durumlarının zorluk düzeyine göre sınıflandırılması sağlanmıştır. Bu aşamada elde edilen veriler ise içerik analizine tabi tutulmuş ve frekans değeri kullanılarak elde edilmiștir. İçerik analizi sözel, yazılı ve diğer materyallerin içerdiği mesajı, anlam ve dilbilgisi açısından nesnel ve sistematik olarak sınıflandırma, sayılara dönüştürme ve çıkarımda bulunma yoluyla sosyal gerçeği araştıran bilimsel bir yaklaşımdır (Tavşancıl ve Aslan, 2001).

\section{Bulgular}

\section{Kars Yöresine Ait Sözsüz Eserlerin Müzikal Analizine İlişkin Bulgular ve Yorumlar}

Yapılan araştırmada TRT repertuar arşivinde yer alan Kars yöresine ait sözsüz (çalgısal) eserlerin, Ağır Bar, Arzuman, Azeri Oyun Havası, Cindavur, Enzeli IV, Kars Oyun Havası I, Kars Oyun Havası II, Kars Oyun Havası III, Kor Oyunu, Kötan Barı, Odalar, Sarı Seyran Barı I, Tamara I, Terekeme eserleri olduğu ve bu eserlerin sayısının 14 olduğu tespit edilmiştir. Kültür bakanlığı kaynaklarında ise; Ağır Bar II, Altın Ömür, Ani Papurisi, Askerani, Ayşat, Azerbaycan, Bar Havası, Baş Açılan, Bu Bahçede, Ceylan, Çele, Demirem, Düz Yallı I, Düz Yallı II, Enzeli I, Enzeli II Enzeli III, Hüner Gösteri Havası, Iğdır Barı, Kamberhan, Karabağ, Kars Oyun Havası, Kırmızı Gül, Nadire Oyun Havası, On Dört, Papuri, Sarı Seyran Barı II, Şeker Oğlan, Tamara II, Tersine, Türkistan Oyun Havası I, Türkistan Oyun Havası II, Türkistan Oyun Havası III, Üç Ayak eserlerinin yer aldığı ve bu eserlerin sayısının 34 olduğu ve TRT ve Kültür bakanlığı repertuarında Kars yöresine ait sözsüz (çalgısal) eser sayısının toplamda 48 olduğu belirlenmiştir. Aynı ismi taşıyan eserlerin Ağır Bar I ve II, Düz Yallı I ve II, Enzeli I, II, III ve IV, Kars Oyun Havası I, II, III ve IV, Sarı Seyran Barı I ve II, Tamara I ve II, Türkistan Oyun Havası I, II ve III eserleri şeklinde olduğu görülmüştür.

Eserlerin müzikal değerlendirilmesine yönelik bulgular kısmında eserlerin isimleri, eserlerde kullanılan TSM müziği makam isimleri, THM müziği ayak dizi isimleri, karar sesleri, ses genişliği, kalın ve ince sesler ölçü birimleri ve değişen ölçü birimleri hakkındaki bilgiler sunulmuştur.

\section{yorumlar}

Kars yöresine ait sözsüz eserlerde kullanılan TSM makam dizilerine ilişkin bulgular ve

Kars yöresine ait sözsüz eserlerde kullanılan TSM makam dizilerinin eserlere göre dağılımı şu şekildedir: İncelenen 48 eser içerisinde \%18.75 oranla 9 eserin Buselik, \% 14.58 oranla 7 eserin Çargâh, \% 10.42 oranla 5 eserin Hicaz, \% 6.25 oranla 3 eserin Hüseyni, \% 4.17 oranla 2 eserin Hüzzam, \% 8.33 oranla 4 eserin Kürdi, \% 14.58 oranla 7 eserin Rast, \% 4.17 oranla 2 eserin Segâh, \% 18.75 oranla 9 eserin Uşşak makam dizisinde olduğu; eserler içerisinde en fazla kullanılan makam dizilerinin \%18.75 oranla (9 eser) Uşşak, yine \% 18.75 oranla (9 eser) Buselik makam dizisinde olduğu, en az kullanılan makam dizilerinin ise \% 4.17 oranla (2 eser) Segâh, yine \% 4.17 oranla (2 eser) Hüzzam makam dizisinde olduğu tespit edilmiştir. 


\section{yorumlar \\ Kars yöresine ait sözsüz eserlerde kullanılan THM ayak dizilerine ilişkin bulgular ve}

Kars yöresine ait sözsüz eserlerde kullanılan THM ayak isimlerinin eserlere göre dağılımı şu şekildedir: İncelenen 48 eser içerisinde \% 39.58 oranla 19 eserin Kerem, \% 29.17 oranla 14 eserin Müstezat, \% 10.42 oranla 5 eserin Garip, \% 8.33 oranla 4 eserin Misket, \% 8.33 oranla 4 eserin Bozlak, $\% 4.17$ oranla 2 eserin Kesik Kerem ayak dizisinde olduğu; en fazla eser Kerem ayak dizisinde (19 eser) en az eser ise Kesik Kerem ( 2 eser) ayak dizilerinde yer almaktadır. Kerem ayak dizisinde yer alan eserlerin fazla olma nedeninin TSM dizisindeki Buselik makam dizisinin karşı1lı̆̆ının Uşşak ve Hüseyni makam dizileri ile birlikte Kerem ayak dizisi olarak kabul edilmesi olduğu gösterilebilir.

\section{Kars yöresine ait sözsüz eserlerin ses genişliğine iliş̧kin bulgular ve yorumlar}

Kars yöresine ait sözsüz eserlerin ses genişliğinin eserlere göre dağılımı şu şekildedir: İncelenen 48 eser içerisinde $\% 35.42$ oranla 17 eserin sekiz ses, \% 18.75 oranla 9 eserin yedi ses, $\% 12.50$ oranla 5 eserin alt ses, $\% 12.50$ oranla 6 eserin alt ses, $\% 10.42$ oranla 5 eserin dokuz ses, $\% 6.25$ oranla 3 eserin on ses, \% 4.17 oranla 2 eserin on bir ses aralığında olduğu; en geniş ses aralığın ise on bir ses ( 2 eser), en dar ses aralığın beş ses ( 6 eser) olduğu tespit edilmiştir.

\section{Kars yöresine ait sözsüz eserlerin karar seslerine ilişkin bulgular ve yorumlar}

Kars yöresine ait sözsüz eserlerde kullanılan karar seslerinin eserlere göre dağılımı şu şekildedir: İncelenen 48 eser içerisinde \% 58.33 oranla 28 eserin La, \%18.75 oranla 9 eserin Do, \% 14.58 oranla 7 eserin Re, \% 6.25 oranla 3 eserin Sol, \% 2.08 oranla 1 eserin Si sesinin karar perdesi (bitiş sesi) olarak kullanıldığı görülmüştür. Eserlerde en fazla karar sesinin La perdesinde (28 eser), en az karar sesinin Si perdesinde (1 eser) kullanılmış olduğu tespit edilmiştir.

\section{yorumlar}

Kars yöresine ait sözsüz eserlerde kullanılan kalın (pest) seslere iliş̧in bulgular ve

Kars yöresine ait sözsüz eserlerde kullanılan kalın seslerin eserlere göre dağılımı şu şekildedir: İncelenen 48 eser içerisinde $\% 45.83$ oranla 22 eserin sol $(\mathrm{G}), \% 29.17$ oranla 14 eserin la (A), \% 14.58 oranla 7 eserin fa diyez (F\#), \% 2.08 oranla 1 eserin sol diyez (G\#), 1 eserin mi (E), 1 eserin fa (F), 1 eserin si (B), 1 eserin do diyez (C\#) olduğu; eserler içerisinde kullanılan en kalın sesin mi (E) olduğu tespit edilmiştir.

\section{Kars yöresine ait sözsüz eserlerde kullanılan tiz (ince) seslere ilişkin bulgular ve yorumlar}

Kars yöresine ait sözsüz eserlerde kullanılan ince seslerin eserlere göre dağılımı şu şekildedir: İncelenen 48 eser içerisinde \%35.42 oranla 17 eserin mi (E2), \% 33.33 oranla 16 eserin sol (G2), \%18.75 oranla 9 eserin la (A2), \%4.17 oranla 2 eserin si (B2), \%4.17 oranla 2 eserin re (D2), \% 2.08 oranla 1 eserin fa (F2), \%2.08 oranla 1 eserin do (C2) olduğu; eserler içerisinde kullanılan en ince sesin mi (E2) olduğu tespit edilmiştir.

\section{Kars yöresine ait sözsüz eserlerde kullanılan ölçü birimlerine ilişkin bulgular ve yorumlar}

Kars yöresine ait sözsüz eserlerde kullanılan ölçü birimlerinin eserlere göre dağ şekildedir: İncelenen 48 eser içerisinde \% 35.42 oranla 17 eserin ölçü birimleri değişen eserler, \% 18.75 oranla 9 eserin $4 / 4^{\prime}$ 'lük, \% 16.67 oranla 8 eserin $6 / 8^{\prime}$ 'lik, \% 16.67 oranla 7 eserin $12 / 8$ 'lik, \% 6.25 oranla 3 eserin $2 / 4^{\prime}$ lük, $\% 2.08$ oranla 1 eserin $21 / 8^{\prime}$ lik, \% 2.08 oranla 1 eserin $3 / 8$ 'lik, $\% 2.08$ oranla 1 eserin 9/8'lik, \% 2.08 oranla 1 eserin 10/8'lik olduğu; eserler içerisinde en fazla kullanılan ölçü biriminin \% 18.75 oranla $4 / 4$ ( 9 eser), en az kullanılan ölçü biriminin ise \% 2.08 oranla 3/8'lük ( 1 eser) ve yine \% 2.08 oranla $21 / 8$ 'lik ( 1 eser) olduğu tespit edilmiştir.

\section{yorumlar}

Kars yöresine ait sözsüz eserlerde ölçü birimleri değişen eserlere ilişkin bulgular ve Kars yöresine ait 48 sözsüz eserde ölçü birimleri değişen eserlerin \% 35.42 oranla 17 eser olduğu ve bu eserlerin toplam sayıya göre dağılımının: \% 10.42 oranla 4/4'lük başlayan ölçü biriminin 6/8'lik ölçü birimi ile sona erdiği( 5 eser), \% 6.25 oranla $2 / 4$ 'lük başlayan ölçü biriminin $6 / 8$ 'lik ölçü birimi ile sona 
erdiği (3 eser), \% 4.17 oranla 4/4'lük başlayan ölçü biriminin 12/8'lik ölçü birimi ile sona erdiği ( 2 eser), $\% 4.17$ oranla 3/8'lik başlayan ölçü biriminin 6/8'lik ölçü birimi ile sona erdiği ( 2 eser), \% 2.08 oranla 9/8'lik başlayan ölçü biriminin 2/4'lük ölçü birimi ile sona erdiği ( 1 eser), $\% 2.08$ oranla 9/8'lik başlayan ölçü biriminin 12/8' lik ölçü birimi ile sona erdiği ( 1 eser), \% 2.08 oranla 10/8'lik başlayan ölçü biriminin 6/8'lik ölçü birimi ile sona erdiği (1 eser), \% 2.08 oranla 12/8'lik başlayan ölçü biriminin 6/8'lik ölçü birimi ile sona erdiği ( 1 eser), \% 2.08 oranla 3/4'lük başlayan ölçü biriminin 9/8'lik ölçü birimi ile sona erdiği (1 eser) olduğu, \% 64.58 oranla 31 eserde ölçü biriminin değişmediği belirlenmiştir. Eser içerisinde ölçü birimlerinin değişimine neden olarak halk danslarının iki bölümlü olarak oynanması olarak gösterilebilir. Ayrıca eserlerin bir kısmının basit vuruş (ikiye bölünen vuruş) olarak kabul edilen 2/4,3/4' ve 4/4'lük olduğu, bir kısmının bileşik vuruş (üçe bölünen vuruş) 3/8, 6/8 ve 12/8'lik, bir eserin ise karma vuruş (ikişerli ve üçerli vuruş) 10/8'lik olduğu tespit edilmiştir. yorumlar

Kars yöresine ait sözsüz eserlerde makam dizileri değişen eserlere ilişkin bulgular ve

Kars yöresine ait sözsüz eserlerde eser içerisinde değişen makam dizilerinin eserlere göre dağılımı şu şekildedir: İncelenen 48 eserden 4'ünün içerisinde iki değişik makam dizisi kullanıldığı; 1 eserin Hüzzam makam dizisinde başlayıp Çargâh makam dizisi ile sona erdiği (\% 2.08 oran), 1 eserin Buselik makam dizisinde başlayıp Uşşak makam dizisi ile sona erdiği (\% 2.08 oran), 1 eserin Segâh makam dizisinde başlayıp Çargâh makam dizisi ile sona erdiği (\% 2.08 oran), 1 eserin Rast makam dizisinde başlayıp Hicaz makam dizisi ile sona erdiği (\% 2.08 oran) tespit edilmiştir. yorumlar

Kars yöresine ait sözsüz eserlerde ayak dizileri değişen eserlere ilişsin bulgular ve

Kars yöresine ait sözsüz eserlerde eser içerisinde değişen ayak dizilerinin eserlere göre dağılımı şu şekildedir: İncelenen 48 eserden 4'ünün içerisinde iki değişik ayak dizisi kullanıldığı, iki eserin Misket ayak dizisinde başlayıp, Müstezat ayak dizisi ile sona erdiği (\% 4.17 oran), bir eserin Müstezat (Buselik) ayak dizisinde başlayıp, Kerem ayak dizisi ile sona erdiği (\% 2.08 oran), bir eserin Müstezat ayak dizisinde başlayıp, Garip ayak dizisi ile sona erdiği (\% 2.08 oran) belirlenmiştir. Makam dizilerinin eserlere göre dağılımı incelendiğinde ise, eserlerin dört farklı makam dizisinde (Hüzzam, Buselik, Segâh, Rast) ve iki farklı ayak dizisinde (Misket, Müstezat) başlamış olduğu görülmüştür. Bu duruma sebep olarak, Segâh ve Hüzzam makam dizilerinin THM terminolojisinde Misket ayak dizisi, Rast ve Buselik makam dizilerinin ise müstezat olarak isimlendirilmiş olmaları gösterilebilir. Dizilerin perde dizilişlerine ve koma değerlerine bakıldığında bu isimlendirmelerin yeterli olmayacağı söylenebilir. Örneğin Müstezat ayak dizisi hem Rast ve Çargâh gibi (majör sayılabilecek) diziler hem de Buselik (minör sayılabilecek) dizileri karşılayacak şekilde kullanılmaktadır.

\section{Kars Yöresine Ait Sözsüz Eserlerin Çalgı Eğitiminde Kullanılabilirlik Durumlarına Yönelik Alan Uzmanı Akademisyenlerin Görüşlerine İlişkin Bulgular}

Bu bölümde Kars yöresine ait sözsüz eserlerin seslendirilmesindeki zorluk düzeyine bağlı olarak farklı öğretim kademelerinde çalgı eğitiminde kullanılabilirliğine ilişkin alan uzmanı akademisyenlerin görüşlerine ilişkin bilgilere yer verilmiştir. 
Tablo 1.

Kars Yöresine Ait Sözsüz Eserlerin Çalg1 Eğitiminde Kullanılmasına İlişkin Uzman Görüşlerine Yönelik Genel Tablo

\begin{tabular}{|c|c|c|c|c|c|c|}
\hline \multirow{2}{*}{ Eserler } & \multicolumn{3}{|c|}{ Güzel Sanatlar Liseleri } & \multicolumn{3}{|c|}{ Lisans Eğitimi } \\
\hline & Basit & Orta & İleri & Basit & Orta & İleri \\
\hline Ağır Bar & 3 & - & - & 3 & - & - \\
\hline Ağır Bar II & 3 & - & - & 3 & - & - \\
\hline Altın Ömür & 3 & - & - & 3 & - & - \\
\hline Ani Papurisi & 3 & - & - & 3 & - & - \\
\hline Arzuman & - & - & 3 & - & 2 & 1 \\
\hline Askerani & - & 3 & - & 3 & - & - \\
\hline Ayşat & 1 & - & 2 & - & 2 & 1 \\
\hline Azerbaycan & 3 & - & - & - & - & 3 \\
\hline Azeri Oyun Havası & 3 & - & - & - & 1 & 2 \\
\hline Bar Havası & 3 & - & - & - & - & 3 \\
\hline Baş Açılan & 3 & - & - & - & 2 & 1 \\
\hline Bu Bahçede & 3 & - & - & 3 & - & - \\
\hline Ceylan & - & 3 & - & 3 & - & - \\
\hline Çele & - & - & 3 & - & 3 & - \\
\hline Cindavur & - & - & 3 & - & 3 & - \\
\hline Demirem & - & - & 3 & - & 2 & 1 \\
\hline Düz Yallı I & 1 & - & 2 & - & 2 & 1 \\
\hline Düz Yallı II & 2 & - & 1 & - & - & 2 \\
\hline Enzeli I & - & - & 3 & - & 3 & - \\
\hline Enzeli II & - & 2 & 1 & 3 & - & - \\
\hline Enzeli III & - & 1 & 2 & 3 & - & - \\
\hline Enzeli IV & - & - & 3 & 2 & 1 & - \\
\hline Hüner Gösteri Havası & 2 & 1 & - & 3 & - & - \\
\hline Iğdır Barı & - & 3 & - & 3 & - & - \\
\hline Kanberhan & - & 3 & - & 3 & - & - \\
\hline Karabağ & 2 & 1 & - & 3 & - & - \\
\hline Kars Oyun Havası I & - & 2 & 1 & 2 & 1 & - \\
\hline Kars Oyun Havası II & - & 1 & 2 & - & 3 & - \\
\hline Kars Oyun Havası III & - & 2 & 1 & 3 & - & - \\
\hline Kars Oyun Havası IV & - & - & 3 & - & 2 & 1 \\
\hline Kırmızı Gül & - & 3 & - & 3 & - & - \\
\hline Kor Oyunu & - & - & 3 & - & 2 & 1 \\
\hline Kötan Barı & - & - & 3 & - & 2 & 1 \\
\hline Nadire Oyun Havası & - & 3 & - & 3 & - & - \\
\hline Odalar & - & 3 & - & 3 & - & - \\
\hline On Dört & 3 & - & - & 3 & - & - \\
\hline Papuri & - & 3 & - & 3 & - & - \\
\hline Sar1 Seyran Barı I & 3 & - & - & 3 & - & - \\
\hline Sar1 Seyran Bar1 II & 2 & 1 & - & 3 & - & - \\
\hline Şeker Oğlan & - & 1 & 2 & 1 & 2 & - \\
\hline Tamara I & 3 & - & - & 3 & - & - \\
\hline Tamara II & - & 3 & - & 3 & - & - \\
\hline Terekeme & - & - & 3 & - & 3 & - \\
\hline Tersine & - & 3 & - & 3 & - & - \\
\hline Türkistan Oyun Havası I & 3 & - & - & 3 & - & - \\
\hline Türkistan Oyun Havası II & 3 & - & - & 3 & - & - \\
\hline Türkistan Oyun Havası III & 3 & - & - & 3 & - & - \\
\hline Üç Ayak & - & 2 & 1 & 3 & - & - \\
\hline
\end{tabular}

Tablo 1'de Kars yöresine ait sözsüz eserlerin güzel sanatlar lisesi ve lisans eğitimi basamağında çalg1 eğitiminde kullanılabilirliği ve seslendirme zorluk düzeylerine yönelik uzman görüşleri yer almaktadır. Buna göre uzmanların güzel sanatlar liselerinde 15 eserin basit düzeyde, 10 eserin orta 
düzeyde, 10 eserin ileri düzeyde olduğuna; lisans basamağ için 28 eserin basit düzeyde, 5 eserin orta, 2 eserin ise ileri düzeyde olduğuna yönelik görüş birliği sağladıkları görülmüştür.

Tablo 2.

Kars Yöresine Ait Sözsüz Eserlerin Güzel Sanatlar Lisesi Eğitimi Düzeyi Çalgı Eğitiminde Kullanılmasına İlişkin Görüş Birliğinde Olunan Eseler

\begin{tabular}{|c|c|c|c|}
\hline \multirow{2}{*}{ Eserler } & \multicolumn{3}{|c|}{ Güzel Sanatlar Liseleri } \\
\hline & Basit & Orta & İleri \\
\hline Ağır Bar & $\mathrm{X}$ & - & - \\
\hline Ağır Bar II & $\mathrm{X}$ & - & - \\
\hline Altın Ömür & $\mathrm{X}$ & - & - \\
\hline Ani Papurisi & $\mathrm{X}$ & - & - \\
\hline Arzuman & - & - & $\mathrm{X}$ \\
\hline Askerani & - & $\mathrm{X}$ & - \\
\hline Azerbaycan & $\mathrm{X}$ & - & - \\
\hline Azeri Oyun Havas1 & $\mathrm{X}$ & - & - \\
\hline Bar Havası & $\mathrm{X}$ & - & - \\
\hline Baş Açılan & $\mathrm{X}$ & - & - \\
\hline Bu Bahçede & $\mathrm{X}$ & - & - \\
\hline Ceylan & - & $\mathrm{X}$ & - \\
\hline Çele & - & - & $\mathrm{X}$ \\
\hline Cindavur & - & - & $\mathrm{X}$ \\
\hline Demirem & - & - & $\mathrm{X}$ \\
\hline Enzeli I & - & - & $\mathrm{X}$ \\
\hline Enzeli IV & - & - & $\mathrm{X}$ \\
\hline Iğdır Barı & - & $\mathrm{X}$ & - \\
\hline Kanberhan & - & $\mathrm{X}$ & - \\
\hline Kars Oyun Havası IV & - & - & $\mathrm{X}$ \\
\hline Kırmızı Gül & - & $\mathrm{X}$ & - \\
\hline Kor Oyunu & - & - & $\mathrm{X}$ \\
\hline Kötan Barı & - & - & $\mathrm{X}$ \\
\hline Nadire Oyun Havası & - & $\mathrm{X}$ & - \\
\hline Odalar & - & $\mathrm{X}$ & - \\
\hline On Dört & $\mathrm{X}$ & - & - \\
\hline Papuri & - & $\mathrm{X}$ & - \\
\hline Sar1 Seyran Bar1 I & $\mathrm{X}$ & - & - \\
\hline Tamara I & $\mathrm{X}$ & - & - \\
\hline Tamara II & - & $\mathrm{X}$ & - \\
\hline Terekeme & - & - & $\mathrm{X}$ \\
\hline Tersine & - & $\mathrm{X}$ & - \\
\hline Türkistan Oyun Havası I & $\mathrm{X}$ & - & - \\
\hline Türkistan Oyun Havası II & $\mathrm{X}$ & - & - \\
\hline Türkistan Oyun Havası III & $\mathrm{X}$ & - & - \\
\hline
\end{tabular}

Tablo 2 incelendiğinde uzmanlar tarafindan Kars yöresine ait 36 sözsüz eserin güzel sanatlar liseleri basamağında çalg1 eğitiminde kullanılabilirliğine ilişkin görüş birliği sağlandıkları belirlenmiştir. Bu eserlerden "A ğır Bar", "Ağır Bar II”, "Altın Ömür”, "Ani Papurisi”, "Azerbaycan”, "Azeri Oyun Havası", "Bar Havası", "Baş Açılan", "Bu Bahçede", "On Dört", "Sarı Seyran Barı I", "Tamara I", "Türkistan Oyun Havası I", "Türkistan Oyun Havası II" ve "Türkistan Oyun Havas1 III" eserlerinin çalgı eğitimi için basit düzey; "Askerani”, "Ceylan”, "Iğdır Barı", "Kanberhan", "Kırmızı Gül”, "Nadire Oyun Havası", "Odalar", "Papuri", "Tamara II" ve "Tersine" eserlerinin orta düzey; "Arzuman", "Çele", "Cindavur", "Demirem”, "Enzeli I", "Enzeli IV”, "Kars Oyun Havası IV”, "Kor Oyunu", "Kötan Barı" ve "Terekeme" eserlerinin ise ileri düzey eserler olduğuna yönelik görüş birliğinde oldukları görülmüştür. 
Tablo 3.

Kars Yöresine Ait Sözsüz Eserlerin Lisans Eğitimi Düzeyi Çalg1 Eğitiminde Kullanılmasına İlişkin Görüş Birliğinde Olunan Eseler

\begin{tabular}{lccc}
\hline \multirow{2}{*}{ Eserler } & & Lisans Ĕ̈itimi & \\
\cline { 2 - 4 } & Basit & Orta & Ileri \\
\hline Ağır Bar & X & - & - \\
\hline Ağır Bar II & $X$ & - & - \\
\hline Altı Ömür & $X$ & - & - \\
\hline Ani Papurisi & $X$ & - & - \\
\hline Askerani & $X$ & - & - \\
\hline Azerbaycan & - & - & $X$ \\
\hline Bar Havası & - & - & $X$ \\
\hline Bu Bahçede & $X$ & - & - \\
\hline Ceylan & $X$ & - & - \\
\hline Cele & - & $X$ & - \\
\hline Cindavur & - & $X$ & - \\
\hline Enzeli I & - & $X$ & - \\
\hline Enzeli II & $X$ & - & - \\
\hline Enzeli III & $X$ & - & - \\
\hline Hüner Gösteri Havası & $X$ & - & - \\
\hline Iğdır Barı & $X$ & - & - \\
\hline Kanberhan & $X$ & - & - \\
\hline Karabağ & $X$ & - & - \\
\hline Kars Oyun Havası II & - & $X$ & - \\
\hline Kars Oyun Havası III & $X$ & - & - \\
\hline Kırmızı Gül & $X$ & - & - \\
\hline Nadire Oyun Havası & $X$ & - & - \\
\hline Odalar & $X$ & - & - \\
\hline On Dört & $X$ & - & - \\
\hline Papuri & $X$ & - & - \\
\hline Sarı Seyran Barı I & $X$ & - & - \\
\hline Sarı Seyran Barı II & $X$ & - & - \\
\hline Tamara I & $X$ & - & - \\
\hline Tamara II & $X$ & - & - \\
\hline Terekeme & - & $X$ & - \\
\hline Tersine & $X$ & - & - \\
\hline Türkistan Oyun Havası I & $X$ & - & - \\
\hline Türkistan Oyun Havası II & $X$ & - & - \\
\hline Türkistan Oyun Havası III & $X$ & - & - \\
\hline Üç Ayak & $X$ & - & - \\
\hline & & $X$ & - \\
\hline
\end{tabular}

Tablo 3 incelendiğinde uzmanlar tarafından Kars yöresine ait 36 sözsüz eserin lisans düzeyi çalg1 eğitiminde kullanılabilirliğine ilişkin görüş birliği sağlandığı belirlenmiştir. Bu eserlerden "Ağır Bar", "A ğır Bar II", “Altın Ömür”, "Ani Papurisi”, "Askerani”, "Bu Bahçede", “Ceylan”, "Enzeli II”, "Enzeli III", "Hüner Gösteri Havası" "Iğdır Barı", "Kanberhan”, "Karabağ", "Kars Oyun Havası III", "Kırmızı Gül”, "Nadire Oyun Havası", "Odalar", "On Dört", "Papuri”, "Sarı Seyran Barı I", "Sarı Seyran Barı II", "Tamara I", "Tamara II", "Tersine", "Türkistan Oyun Havası I", "Türkistan Oyun Havası II" "Türkistan Oyun Havası III" ve "Üç Ayak" eserlerinin çalgı eğitimi için basit düzey; "Çele", "Cindavur", "Enzeli I", "Kars Oyun Havası II" ve "Terekeme" eserlerinin orta düzey; "Azerbaycan"” ve "Bar Havası" eserlerinin ise ileri düzey eserler olduğuna yönelik görüş birliğinde oldukları görülmüştür.

\section{Tartışma, Sonuç ve Öneriler}

Araştırma sonucunda Kars yöresine ait toplam 48 adet sözsüz eser olduğu tespit edilmiştir. Müzikal analizi yapılan eserlerde en fazla kullanılan makam dizilerinin \%18.75 oranla Uşşak ve Buselik makam dizisinde olduğu, en az kullanılan makam dizilerinin ise \%4.17 oranla Segâh ve Hüzzam makamı dizisinde olduğu belirlenmiştir. Eserlerde en fazla eserin Kerem ayak dizisinde (19 eser), en az eserin 
ise Kesik Kerem (2 eser) ayak dizisinde olduğu görülmüştür. İncelenen eserlerin en dar 5'li, en geniş 11 'li ses aralığına sahip olduğu sonucuna ulaşılmıştır. Eserlerde kullanılan karar seslerine ilişskin olarak, en fazla La perdesinin en az Si perdesinin kullanıldığı belirlenmiştir. Eserler içerisinde kullanılan en kalın (pest) sesin $\mathrm{Mi}$, en ince (tiz) sesin La2 olduğu sonucuna ulaşılıışır. Eserler içerisinde kullanılan en fazla ölçü biriminin 4/4, en az kullanılan ölçü biriminin ise 3/8'lik ve $21 / 8$ 'lik olduğu sonucuna ulaşılmıştır.

Analizi yapılan toplam 48 eserden $17^{\prime}$ 'sinin içerisinde iki değişik ölçü biriminin kullanıldığı, otuz bir eserde ölçü biriminin değişmediği belirlenmiştir. Ayrıca incelenen toplam 48 eserden 4'ünün içerisinde iki değişik makam dizisi kullanıldığı sonucuna ulaşılmıştır.

Alan yazın incelendiğinde birçok yöre eserinin müzikal çözümlemelerinin yapıldı̆̆ 1 araştırmalara rastlanmaktadır. Demir (1999) Denizli türkülerini, Karagenç (1999) Kütahya türkülerini, Öztürk (2004) Kerkük türkülerini, Şengül (2004), İnanıc1 ve Sağer (2017) Erzurum türkülerini, Eroğlu (2005) Kırıkkale türkülerini, Demir (2007) Kemaliye (Eğin) türkülerini, Kınık (2007) Kayseri türkülerini, Ateş (2008) Şarkışla yöresine ait türküleri, Yıldırım (2008), Teke yöresinde icra edilen gurbet havalarını, Şenel (2009) Nevşehir türkülerini, Tufan (2010) Manisa yöresine ait zeybek ezgilerini, Türkay (2010) İzmir ili Cumaovası yöresi zeybeklerini, Eroğlu (2011) Arguvan yöresinde icra edilen semahları, Gök (2011) Teke yöresi ve Muğla zeybeklerini, Açar (2014) kına türkülerini, Akyıldız (2016) Burdur türkülerini, Özer (2015) Samsun türkülerini, Arslan (2016) Tokat türkülerini, Tatlıbal (2016) Azerbaycan türkülerini, Çalık (2018) Doğu Karadeniz ve Doğu Anadolu yörelerine ait türküleri çözümleyerek müzikal analizlerini yapmışlardır. Yapılan bu analizler sonucunda, bu çalışmayla benzer şekilde incelenen bölge halk müziklerinin TSM makam dizileri, THM ayak dizileri, ses genişlikleri, karar sesleri ve ölçü birimleri tespit edilmiştir.

Araştırma sonucunda alan uzmanlarının Kars yöresine ait sözsüz eserlerin çalgı eğitiminde kullanılmasına yönelik olarak güzel sanatlar liseleri için 16 eserin basit düzeyde, 10 eserin orta düzeyde, 10 eserin ileri düzeyde olduğuna; lisans basamağı için 29 eserin basit düzeyde, 5 eserin orta, 2 eserin ise ileri düzeyde olduğuna yönelik görüş birliği sağladıkları görülmüştür. Bu sonuçlar, yöresel ve ulusal müzik eserlerinin, müzik eğitimi alanında kullanılmasına yönelik yapılan diğer çalışmalarla da desteklenmektedir. Arabul (2016) Kars yöresine ait kayıt altına alınmamış oyun ezgilerini notaya almış, makamsal ve ritmik yönden analizlerini yaparak bu ezgilerin müzik eğitiminde kullanılabilir olduğunu belirlemiştir. Benzer şekilde Terzioğlu (2015) Ağrı, Evsen (2018) Antalya, Balbay (2018), Şirin (2018) Konya ve Aksaray yöresine ait halk ezgilerini incelemiş ve bu ezgilerin müzik eğitiminde kullanılabilir olduğunu belirlemişlerdir.

Kars yöresine ait eserlerin müzikal analizi ve bu eserlerin müzik eğitiminde kullanılma durumuna yönelik yapılan tespitler sonucunda

- Araştırmada Kars yöresine ait sözsüz eserlerin müzikal analizi ve çalg1 eğitiminde kullanılabilirliği araştırılmıştır. Kars yöresine ait diğer eserlerin (halk dansları, âşık-ozan müziği, seyitlik oyun ezgileri vb.) müzikal analizlerinin yapılması ve müzik eğitiminin farklı boyutlarında kullanılabilirliğine yönelik benzer çalışmaların yapılması,

- Araştırmada Kars yöresine ait sözsüz eserlerin çalg1 eğitiminde kullanılabilirliği uzman görüşlerine dayalı olarak belirlenmeye çalışılmıştır. Benzer çalışmaların deneysel yöntem gibi farklı türden yöntemlerle araştırılarak yöre eserlerinin çalgı eğitiminde kullanımının etkisinin ortaya çıkarılması,

- Derlenen türkülerin kültürümüzün aktarılması ve yaşatılması amacıyla tescillenmesi, genel, özengen ve mesleki müzik eğitimin farklı basamaklarındaki derslerde kullanılmak üzere siniflandirilmasi,

- Türkiye'nin bütün yörelerine ait türkülerin benzer yöntemlerle analiz edilmesi ve eğitim materyali olarak kullanılmasına yönelik çalışmalar yapılması,

- Popüler olmayan ve daha az bilinen geleneksel müziklerin toplumun beğenisine sunulması ve müzik eğitimi veren kurumlarda eğitim materyali olarak kullanılması önerilebilir. 


\section{Kaynakça}

Açar, Y. (2014). TRT Türk halk müziği repertuarında bulunan kına türkülerinin, makam dizileri, usul ve güfte yönünden analizi (Yayımlanmamış Yüksek Lisans Tezi). Erzurum: Atatürk Üniversitesi.

Akyıldız, S. G. (2016). Burdur yöresi Türk halk müziği ve özellikleri (Yayımlanmamış Doktora Tezi). Konya: Necmettin Erbakan Üniversitesi.

Arabul, D. (2016). Kars yöresinde kayıt altına alınmamış mahalli oyunların ezgilerinin derlenmesi ve bunların müzik eğitiminde kullanılabilirliği (Yayımlanmamış Yüksek Lisans Tezi). Erzurum: Atatürk Üniversitesi.

Arslan, S. (2016).Tokat yöresi halk ezgilerinin müzikal analizi (Yayımlanmamış Yüksek Lisans Tezi). Ordu: Ordu Üniversitesi.

Ateş, M. (2008). TRT Repertuvarındaki Şarkışla yöresine ait türkülerin incelenmesi (Yayımlanmamış Yüksek Lisans Tezi). Kayseri: Erciyes Üniversitesi.

Avşar, M. (2018). Kodaly yaklaşımına göre uygulanan armoni dersinin başarıya, tutuma ve performansa etkisi. (Yayımlanmamış Doktora Tezi). İstanbul: Marmara Üniversitesi.

Balbay, T. (2018). Konya ili Karacadağ yöresi halk müziği ve ülkemiz müzik eğitimindeki yeri (Yayımlanmamış Yüksek Lisans Tezi). Konya: Necmettin Erbakan Üniversitesi.

Çalık, B. (2018). TRT repertuvarında bulunan Doğu Karadeniz ve Doğu Anadolu yörelerine ait hicaz karakterli Türkülerin ritmik yapı ve makamsal yönlerden analizi (Yayımlanmamış Yüksek Lisans Tezi). Samsun: Ondokuz Mayss Üniversitesi.

Demir, S. (2007).Kemaliye (Ĕ̈in) yöresi halk müziğinin incelenmesi (Yayımlanmamış Yüksek Lisans Tezi). Sakarya: Sakarya Üniversitesi.

Demir, Z. (1999). TRT repertuvarında Denizli türkülerinin makam-ayak, tür ve usul yönünden incelenmesi (Yayımlanmamış Yüksek Lisans Tezi). İzmir: Ege Üniversitesi.

Demirel, Ö. (2012). Eğitim sözlüğü. Ankara: Pegem Yayınevi.

Demirsipahi, C. (1975). Türk halk oyunları. Ankara: TTK Basımevi.

Emnalar, A. (1998). Tüm yönleriyle Türk halk müziği ve nazariyatı. İzmir: Ege Üniversitesi Basımevi.

Eroğlu, D. K. (2005). TRT repertuvarındaki Kırıkkale türkülerinin ezgisel yapı, makam-ayak nazım türü ve usul yönünden incelenmesine yönelik bir çalışma (Yayımlanmamış Yüksek Lisans Tezi). Konya: Selçuk Üniversitesi.

Eroğlu, S. (2011).Arguvan yöresinde icra edilen semahların müzikal analizi (Yayımlanmamış Yüksek Lisans Tezi). İstanbul: İstanbul Teknik Üniversitesi.

Evsen, F. (2018).Antalya yöresi Türk halk müziği ezgilerinin müzikal- edebi analizi ve müzik eğitiminde kullanılabilirliğinin incelenmesi (Yayımlanmamış Yüksek Lisans Tezi). Konya: Necmettin Erbakan Üniversitesi.

Gök, S. (2011).Teke yöresi ve Muğla zeybeklerinin tür, ayak, tavır, usul ve söz yönünden incelenmesi (Yayımlanmamış Yüksek Lisans Tezi). Konya: Selçuk Üniversitesi.

Görgen, İ. (2017).Eğitimde program geliştirme. (4. Baskı). Ankara: Anı Yayınc1lık.

Gürgen, E.T. (2007). Orff-Schulwerk ve Kodaly yönteminin vokal doğaçlama, müziksel işitme ve şarkı söyleme becerileri üzerindeki etkileri (Yayımlanmamış Doktora Tezi). İzmir: Dokuz Eylül Üniversitesi.

İnanıc1, M. K. ve Sağer, T. (2017). Erzurum yöresine ait sözsüz eserlerin ezgi analizi. TURAN: Stratejik Araştırmalar Merkezi, 9(36), 340-348.

İnanıc1, M. K. (2017). Bağlama eğitiminde yöresel tavırların ögretimine yönelik bir model önerisi (Yayımlanmamış Doktora Tezi). Malaya: İnönü Üniversitesi.

Karagenç, M. (1999) TRT repertuvarında bulunan Kütahya türkülerinin makam-ayak, tür ve usul yönünden incelenmesi (Yayımlanmamış Yüksek Lisans Tezi). İzmir: Ege Üniversitesi.

Karasar, N. (2007). Bilimsel araştırma yöntemi (17. Baskı). Ankara: Nobel Yayın Dağıtım.

Kınık, M. (2007). Kayseri ve yöresi türkülerinin müziksel tahlili (Yayımlanmamış Yüksek Lisans Tezi). Kayseri: Erciyes Üniversitesi.

Kuş, E.(2003). Sosyal bilimlerde araştırma teknikleri nitel mi, nicel mi? Ankara: Anı Yayıncılık.

Küçük, B. (2019). Kodaly ve Dalcroze yaklaşımlarlyla oluşturulmuş etkinliklerin 5 E modeline göre tasarlanan ilkokul 3. sınıf müzik derslerinde kullanımı (Yayımlanmamış Doktora Tezi). İstanbul: Marmara Üniversitesi. 
Merriam, S. (1998). Qualitative research and case study applications in education. Revised and expanded from case study research in education. San Francisco: JB Printing.

Özer, L. (2015). Samsun yöresi Türk halk müziği ezgilerinin müzikal ve edebi yönden incelenmesine yönelik bir çalışma (Yayımlanmamış Yüksek Lisans Tezi). Konya: Necmettin Erbakan Üniversitesi.

Öztürk, O. (2004) TRT repertuvarındaki Kerkük türkülerinin tür ve biçim yönünden incelenmesi (Yayımlanmamış Yüksek Lisans Tezi). İzmir: Ege Üniversitesi.

Peşinci, F. A. (2014). Kodaly yönteminin Saygun ve Bartók piyano repertuarına uygulanması (Yayımlanmamış Yüksek Lisans Tezi). İstanbul: Haliç Üniversitesi.

Şenel, Ü. (2009) Nevşehir yöresi türkülerinin melodik yapı bakımından analizi (Yayımlanmamış Yüksek Lisans Tezi). Kayseri: Erciyes Üniversitesi.

Şengül, M. (2004) TRT repertuvarında bulunan Erzurum türkülerinin makam-ayak, tür-biçim ve usul yönünden incelenmesi (Yayımlanmamış Yüksek Lisans Tezi). İzmir: Ege Üniversitesi.

Şirin A. K. (2018).Aksaray yöresine kayttl sözlü türkülerin ilk ve orta ögretim düzeyinde eğitim müziği olarak düzenlenmesi (Yayımlanmamış Yüksek Lisans Tezi). Konya: Necmettin Erbakan Üniversitesi.

Tatlıbal, B. (2016) TRT repertuarına girmiş Azerbaycan türkülerinin müzikal analizi (Yayımlanmamış Yüksek Lisans Tezi). İstanbul: Haliç Üniversitesi.

Tavşanc1l, E. ve Aslan E. (2001). İçerik analizi ve uygulama örnekleri. İstanbul: Epsilon.

Terzioğlu, A. M. (2015). A $\breve{g r l ~ y o ̈ r e s i n d e ~ k a y ı t ~ a l t ı n a ~ a l ı n m a m ı s ̧ ~ t u ̈ r k u ̈ l e r i n ~ d e r l e n e r e k ~ e g ̆ i t i m ~ m u ̈ z i g ̆ i ~}$ açısından incelenmesi (Yayımlanmamış Yüksek Lisans Tezi). Erzurum: Atatürk Üniversitesi.

Tufan, E. M. (2010).Manisa yöresine ait zeybek ezgilerinin incelenmesi (Yayımlanmamış Yüksek Lisans Tezi). Kayseri: Erciyes Üniversitesi.

Tufan, S. (2011). Müzik öğretmeni adaylarının Dalcroze-Kodaly ve Orff yaklaşımlarlyla ilgili görüşleri ile bu yaklaşımların adayların öğretmenlik uygulamasına ilişkin tutumlarına olan etkisi. (Yayımlanmamış Yüksek Lisans Tezi). İstanbul: Marmara Üniversitesi.

Türkay, M. K. (2010). İzmir ili Cumaovası yöresi zeybeklerinin ezgi ve ritim yapısı bakımından incelenmesi (Yayımlanmamış Yüksek Lisans Tezi). Sakarya: Sakarya Üniversitesi.

Uçan, A. (1997). Müzik eğitimi. (2. Baskı). Ankara: Müzik Ansiklopedisi Yayınları.

Yıldırım, A. ve Şimşek, H. (2011). Sosyal Bilimlerde Nitel Araştırma Yöntemleri (8.baskı). Ankara: Seçkin Yayıncilık.

Yıldırım, B. (2008). Teke yöresinde icra edilen gurbet havalarında müzikal açıdan tavır farklılıkları (Yayımlanmamış Yüksek Lisans Tezi). İstanbul: Haliç Üniversitesi. 


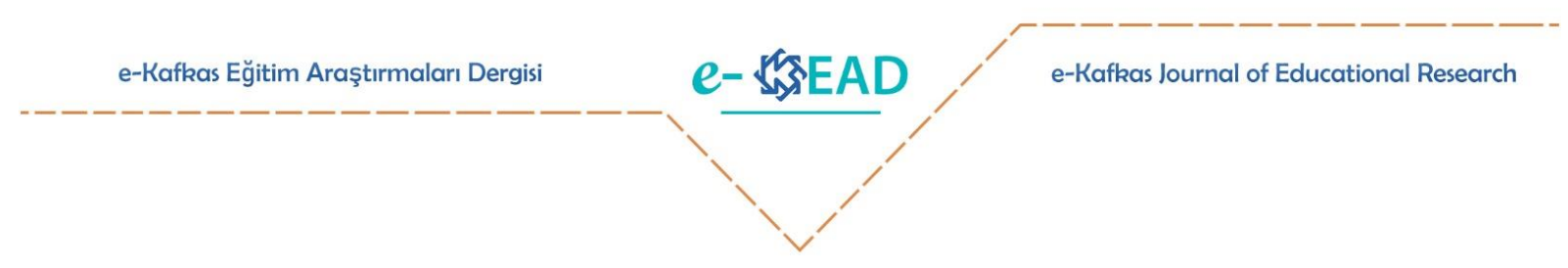

\section{Musical Analysis of Non-Verbal Works Which are belong to Kars Region and Their Usability in Instrument Education}

\section{Şermin Uluman Murat Kâmil İnanıcı}

To cite this article: Uluman, Ş. ve İnanıcı, M. K. (2020). Kars yöresine ait sözsüz eserlerin müzikal analizi ve çalg1 eğitiminde kullanılabilirliği. e- Kafkas Eğitim Araştırmaları Dergisi, $7, \quad 458-472$. doi:10.30900/kafkasegt.757964

\section{Research article}

Received: 25.06 .2020

Accepted: 01.12.2020

\section{Introduction}

In music education, it is important to use local music as training material on the road from local to national, from national to universal, and to transfer the cultural values which are in danger of being forgotten and lost, to the next generations through general vocational and attentive music education. For this reason, it is important to examine the melodically and rhythmic properties of folk music works through music education in both the field of education and in terms of ensuring cultural continuity.

In the literature, there are many academic studies on researching and analyzing folk works of various regions and benefiting from different stages of music education understanding. As a result of the investigations that were made, because the musical analysis of Turkish folk music non-verbal works of Kars region has not been made yet and the direction of utilization in music education has not been evaluated it is thought that it can be important in terms of the original value of this study.

In this study, it is aimed to examine the non-verbal works of Turkish folk music of the Kars region from a musical point of view and to determine the usability of these pieces in instrument education in institutions providing vocational music education. In line with this main purpose, the musical evaluation of Turkish folk music non-verbal works belonging to the Kars region sourced from TRT and the Ministry of Culture as a result of document analysis and what are the opinions of expert academicians about the usability of these works in instrument training constitute the problem of this study. Depending on this problem, the following questions were sought in the study:

Belonging to the Kars region sourced by TRT and the Ministry of Culture

- What are the document analysis findings of nonverbal works?

- What are the opinions of academicians who are experts in the field regarding the usability of non-verbal works in instrument training in institutions providing vocational music education?

\section{Method}

\section{Research Model}

The research is designed in a qualitative research model. Qualitative studies are works in which qualitative data collection methods such as observation, interview, and document review are used, and the process of revealing perceptions and events in their natural environment realistically and holistically is followed (Yıldırım \& Şimşek, 2011). In this direction, the research is designed in two dimensions. In the first dimension of the study, the document analysis method is used to make the musical analysis of non-verbal works of Turkish folk music of the Kars region. Documents that constitute the basic source of the document analysis method can be classified as public records, personal documents, popular 
culture documents, and visual documents containing films, videos, and pictures (Merriam, 1998). In the research, the non-verbal works belonging to the Kars region in the TRT repertoire and the sources of the Ministry of Culture have been determined by the researchers to determine the non-verbal works of Turkish folk music of the Kars region. The maqam sequences of the detected non-verbal works have been examined musically by the researchers to determine the units of measure, navigational characteristics, pitch, high and low sounds. Possible mistakes have been corrected by taking the opinions of academicians who are experts in the field regarding the accuracy levels of the determination of the maqam scales, measurement units, navigational, pitch, high-pitched and low-pitched sounds of the Turkish folk music of the Kars region analyzed by the researchers. In the second dimension of the study, interviews have been conducted with field experts regarding the usability of the musical pieces examined in the vocational music education in fine arts high schools and undergraduate education instrument training. The interview is a purposeful interview in which pre-prepared questions are asked and the other person answers the questions (Kuş, 2003).

\section{Working Group}

In the research, 48 non-verbal works of Turkish folk music belonging to the Kars region, which are in the TRT repertoire and Ministry of Culture, were used for musical analysis. To determine the usability of the analyzed works in instrument education, the opinions of 3 academicians who are experts in the field were consulted. In determining academics, criteria such as knowing the local music and being an expert in instrument training were taken as a basis. In this context, 3 academicians working at Kafkas University State Conservatory and meeting these criteria formed the expert group of the research.

\section{Data Collection Tools}

Non-verbal works of the Kars region, which are found in the TRT repertoire and Ministry of Culture sources in the research: maqam sequences, measurement units, navigational characteristics, sound width, treble, and pes were musically examined by the researchers to determine the sounds. Possible mistakes were corrected by taking the opinions of academicians who are experts in the accuracy levels of the analysis and determinations made by the researchers. The correctness of the analysis of the works was tried to be determined by the "expert opinion form" prepared by the researcher.

In the second stage of the research, to determine the usability of Turkish folk music non-verbal works of the Kars region analyzed musically in musical instrument education, an interview form that was prepared in line with expert opinions and related field literature was used intended for field expert. In the interview, there are questions regarding the results of the musical analysis of the Kars region Turkish folk music non-verbal works and their usability status in instrument education concerning their classification in terms of difficulty levels.

\section{Data Analysis}

Descriptive analysis was used to analyze the data revealed in the research. In the research, the works obtained through the document analysis aiming to analyze non-verbal works belonging to the Kars region, which are located in the TRT repertoire and the Ministry of Culture, and Works, which its musical analysis was made were analyzed by descriptive analysis. Data analysis results were expressed in frequency and percentage values. In the second stage of the research, the selected works were presented to the opinions of 3 academicians who are experts in the field of music, and their usability status in instrument education was classified according to the difficulty level. The data gathered at this stage were obtained using the frequency value.

\section{Findings}

Based on the document review was made, it was determined that there are 48 non-verbal works in the Kars region. When the findings related to Turkish music series used in non-verbal works of the Kars region were examined, it was concluded that the most used maqam series were in the Uşşak and Buselik maqam sequence with a rate of $18.75 \%$, while the least used maqam sequences were in the Segâh and Hüzzam maqam sequence with a rate of $4.17 \%$. When the findings related to the Turkish folk music foot sequence used in non-verbal works belonging to the Kars region were examined, it was concluded that most works were in the Kerem foot sequence (19 works) and the least was in the Kesik Kerem ( 2 works) foot sequence. When the findings related to the sound widths of non-verbal works 
belonging to the Kars region were examined, it was concluded that the works had the narrowest quintet and the widest 11 sound range. When the findings related to the decision sounds used in non-verbal works belonging to the Kars region were examined, it was concluded that as the decisive voice, the La curtain was the most used and the Si curtain was the least used. When the findings related to the thick (pes) sounds used in non-verbal works belonging to the Kars region were examined, it was concluded that the thickest sound used in the works was the Mi sound. When the findings related to the fine (treble) sounds used in non-verbal works belonging to the Kars region were examined, it was concluded that the thinnest sound used in the works was La2. When the findings related to the units of measurement used in non-verbal works belonging to the Kars region were examined, it was concluded that the most used unit of measurement in the works was $4 / 4$, and the least used unit was $3 / 8$ and $21 / 8$. When the findings related to the works which have varying units of measure in non-verbal works belonging to the Kars region were examined, It was concluded that two different units of measurement were used in 17 out of 48 works, the unit of measurement did not change in 30 works. When the findings related to the works with changing maqam sequence in non-verbal works belonging to the Kars region were examined, it was concluded that four out of 48 works were used in 2 different maqam sequence.

In addition, as a result of the research, for the use of non-verbal works belonging to the Kars region in instrument training of the field experts, for fine arts high schools, 16 works were at a simple level, 10 works were at an intermediate level, 10 were at an advanced level; for the undergraduate level, it was seen that they provide a consensus that 29 works were at the basic level, 5 works were at the intermediate level, 2 works were at an advanced level.

\section{Discussion, Conclusion, and Recommendations}

According to the research results, Turkish folk music non-verbal works belonging to the Kars region were examined in terms of sound regions, thin and thick sounds, measurement units, maqam, and foot sequence, and as a result, it was observed that the works include rhythmic and melodic diversity, and this diversity would contribute to the literature of instrument education. These results were supported by other studies on the use of local and national musical works in the field of music education. Arabul (2016) notes the unrecorded play works belonging to the Kars region and by analyzing them in terms of maqam and rhythmic aspects she/he determined that these works can be used in music education. Similarly, Terzioğlu (2015) examined the folk works belong to Ağrı, Evsen (2018) Antalya, Balbay (2018), Şirin (2018) Konya, and Aksaray and determined that these works can be used in music education. In the light of these results, it can be suggested to make the musical analysis of other works belonging to the Kars region and to carry out similar studies on the usability of music education in different dimensions, and to investigate the studies by experimental methods. 